\title{
Multiple Pulp Stones: A Case Report
}

\author{
Nurhat Ozkalaycia \\ A. Zeynep Zengin ${ }^{b}$ \\ Selma Elekdag Turk ${ }^{c}$ \\ A. Pinar Sumer ${ }^{d}$ \\ Bilinc Bulucue \\ Tugrul Kirtiloglu
}

\section{ABSTRACT}

Pulp stones are usually found in the pulp chamber. Radiographically, they appear as radiopaque structures in the pulp chambers or root canals of individual teeth. Generalized pulp stones throughout the dentition are usually associated with systemic or genetic disorders of the dentine. This report presents an unusual case of a 13-year-old girl with generalized pulp stones with clinically normal crowns. The patient's main complaint was a crossbite affecting all permanent canines. Radiographic examination revealed multiple pulp stones and several teeth with atypically shaped roots. Orthodontic treatment, gingivoplasty, and esthetic restorations were performed, thus using a multidisciplinary approach to establish functionally and esthetically sound dentition. (Eur J Dent 2011;5:210-214)

Key words: Multiple pulp stones; Pulpal calcifications; Orthodontic treatment.

Research Assistant, Zonguldak Karaelmas University, Faculty of Dentistry, Department of Orthodontics, Zonguldak, Turkey.

b Assistant Professor, Ondokuzmayis University, Faculty of Dentistry, Department of Oral Diagnosis and Radiology, Samsun, Turkey.

c Assistant Professor, Ondokuzmayis University, Faculty of Dentistry, Department of Orthodontics, Samsun, Turkey.

d Associate Professor, Ondokuzmayis University, Faculty of Dentistry, Department of Oral Diagnosis and Radiology, Samsun, Turkey.

e Professor, Zonguldak Karaelmas University, Faculty of Dentistry, Department of Restorative

Dentistry and Endodontics, Zonguldak, Turkey.

f Assistant Professor, Ondokuzmayis University, Faculty of Dentistry, Department of Periodontology, Samsun, Turkey.

- Corresponding author: A. Zeynep Zengin Department of Oral Diagnosis and Radiology, Faculty of Dentistry, Ondokuz Mayis University, Kurupelit 55139, Samsun, Turkey.

Phone: +90 362 3121919/3012 Fax: +90 3624576032

E-mail: dtzeynep78ahotmail.com

\section{INTRODUCTION}

Pulp stones are foci of calcification in the dental pulp. Their cause is unknown, and no firm evidence exists that they are associated with any systemic or pulpal disturbance. ${ }^{1}$

Pulp stones are radiologically variable; they may occur as a single dense mass or as several small radiopacities seen within pulp chambers or root canals, or may extend from the pulp chamber into root canals. They occur in all tooth types but occur most commonly in molars. ${ }^{1}$ Pulp calcifications occurring throughout the dentition are uncommon and are usually associated with systemic or genetic disorders of dentine. ${ }^{2}$

Dentine dysplasia (DD) is an autosomal dominant trait that resembles opalescent dentin. Two types have been described. ${ }^{1}$ Type I, also called radicular dentin dysplasia, primarily affects the root portions of both primary and permanent teeth 
and produces teeth with shortened and periapical radiolucencies. ${ }^{3}$ Type $\mathrm{II}$, also called coronal pulp dentin dysplasia, is characterized by large pulp chambers containing denticles in permanent teeth and total obliteration of the pulp chambers in primary teeth. ${ }^{4}$

According to $0^{\prime}$ Carroll et $\mathrm{al}^{5}{ }^{5}$ the permanent teeth in DD1 can have any of 4 fairly distinct radiographic appearances:

1. Complete obliteration of pulp chambers and no root development with many periapical radiolucent areas (DD1a).

2. Horizontal, crescent-shaped, radiolucent pulpal remnants and few millimeters of root development with many periapical radiolucent areas (DD1b).

3. Two horizontal, crescent-shaped, radiolucent lines and significant but incomplete root development, with or without periapical radiolucent areas (DD1C).

4. Visible pulp chambers and oval pulp stones in the coronal third of the canal, with bulging of the root around the stone, and few, if any, periapical radiolucent areas (DD1d).

Localized pulp stones are microscopically apparent in more than half the teeth of young people. ${ }^{1}$ However, pulp stones extending to the entire dentition are infrequent. Radiographic diagnosis and a multidisciplinary approach are of paramount importance for successful treatment in cases of generalized pulp stones. The purpose of this report is to present the multidisciplinary treatment that can be used for large multiple pulp stones.

\section{CASE REPORT}

A 13-year-old girl was referred to the department of orthodontics for correction of a crossbite affecting the upper permanent canines. Her medical and family history was unremarkable, and she had a normal growth pattern. Extraoral examination revealed a symmetric face, a normal lower facial height, and a convex profile (Figure 1). Intraoral examination showed a Class 1 molar relationship with congenitally missing upper lateral incisors. The permanent upper canines, which had erupted into the missing lateral incisor space, were in crossbite. The retained deciduous canines were located distal to the permanent canines. The overjet and overbite were $1 \mathrm{~mm}$ and $3 \mathrm{~mm}$, respectively. The color and morphology of the crowns were normal. The ANB and SNGoGn angles were $2.5^{\circ}$ and $38^{\circ}$, respectively. The upper incisor to maxillary plane angle was normal, i.e., $112^{\circ}$. Both periapical and panoramic radiographs revealed pulp stones and several teeth with atypically shaped roots (Figure 1). The pulp stones were located at the middle or coronal third of the roots, with the roots bulging around the pulpal calcifications.

We treated the anterior crossbite with a fixed appliance for the buccal movement of the upper permanent canines and subsequently performed esthetic restorations of the permanent and deciduous canines. Informed consent for the treatment was obtained prior to the procedure. Maxillary molar teeth were banded, and pre-adjusted fixed appliances (22-inch slot MBT prescription; American Orthodontics, Sheboygan, Winconsin, USA) were placed in the maxillary arch for leveling and alignment. A 0.014-inch NiTi arch wire (American Orthodontics, Sheboygan, Winconsin, USAl was inserted, bypassing the upper permanent canine teeth. Four weeks later, open coils (100 gr; American Orthodontics, Sheboygan, Winconsin, USA) were placed to provide the necessary space for the permanent canines, and were removed after sufficient space was created. The upper canine teeth were bonded. A 0.014-inch NiTi arch wire was reinserted and ligatured to the upper canines. The bite was opened using the Güray instant bite raiser (GAC International, Islandia, New York, USA). The anterior cross bite was corrected within 8 months. For final detailing, a 0.016 -inch stainless steel arch wire (American Orthodontics, Sheboygan, Winconsin, USAl was used. At the end of the treatment, both panoramic and periapical radiographs showed a slight blunting of the roots of the upper deciduous and permanent canines. The patient was referred to the department of periodontology for gingivoplasty, and to the department of operative dentistry for esthetic restorations of the anterior teeth (Figure 2).

\section{DISCUSSION}

Pulp stones vary in size, ranging from microscopic particles to larger masses that almost obliterate the pulp chamber with only the large masses being radiographically apparent. ${ }^{1}$ Many prevalence studies have identified pulp stones using radiographic criteria. Tamse et $\mathrm{al}^{6}$ examined 
both periapical and bitewing radiographs and showed that $20.7 \%$ of the teeth had pulp stones. Ranjitkar et $\mathrm{al}^{7}$ examined the prevalence of pulp stones in an Australian population and found pulp stones in $10 \%$ of the teeth. In a group of Turkish dental patients, pulp stones were found in $12 \%$ of the subjects and $5 \%$ of the teeth. ${ }^{8}$
In the present case, radiographic examination revealed large pulp stones in several permanent teeth. These pulp stones were located in the middle or coronal third of the roots. There was no evidence of the periapical radiolucencies that have been reported in dentin dysplasia type 1 . Although it is difficult to establish a definitive di-

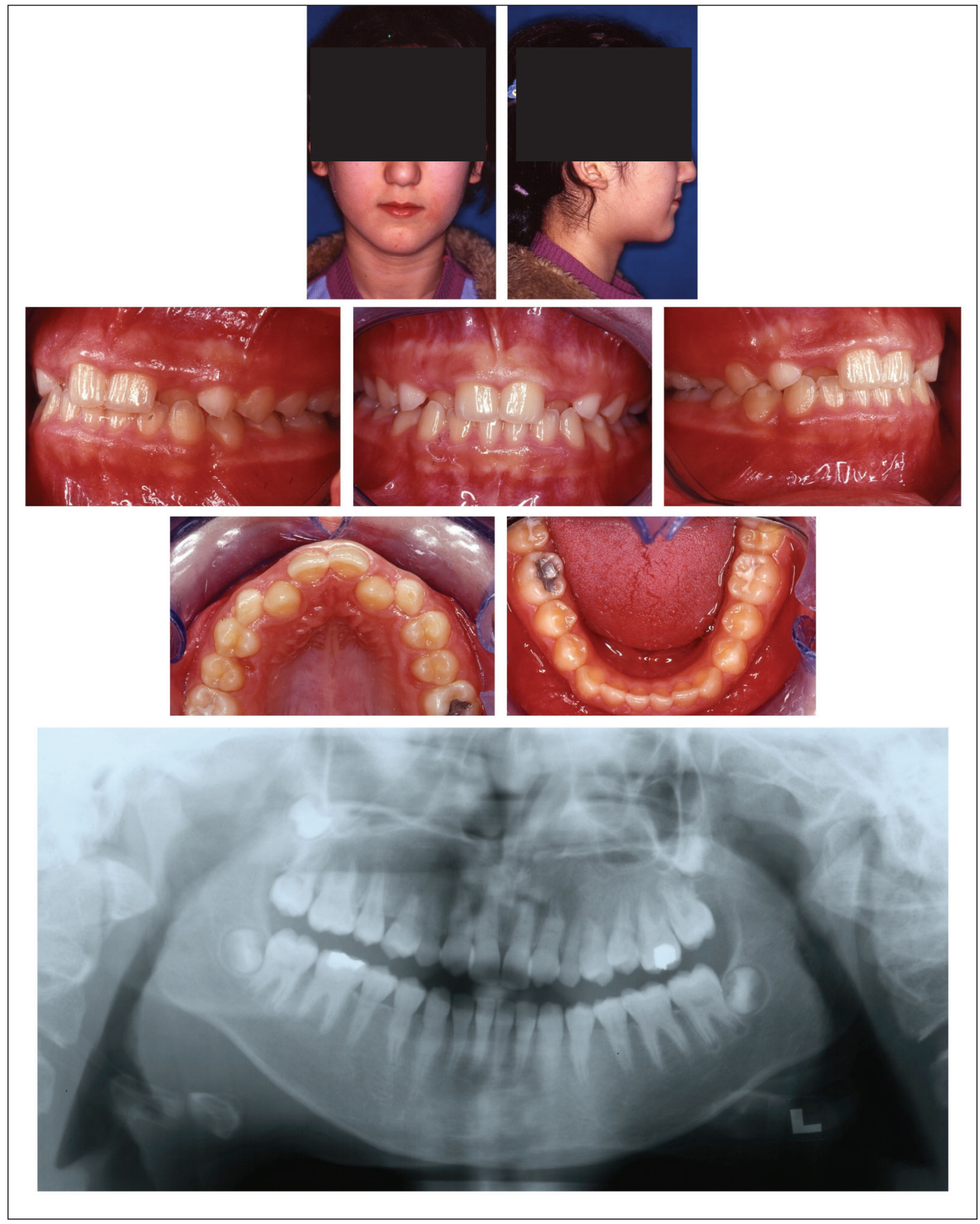

Figure 1. Pretreatment photographs and panoramic radiograph. 


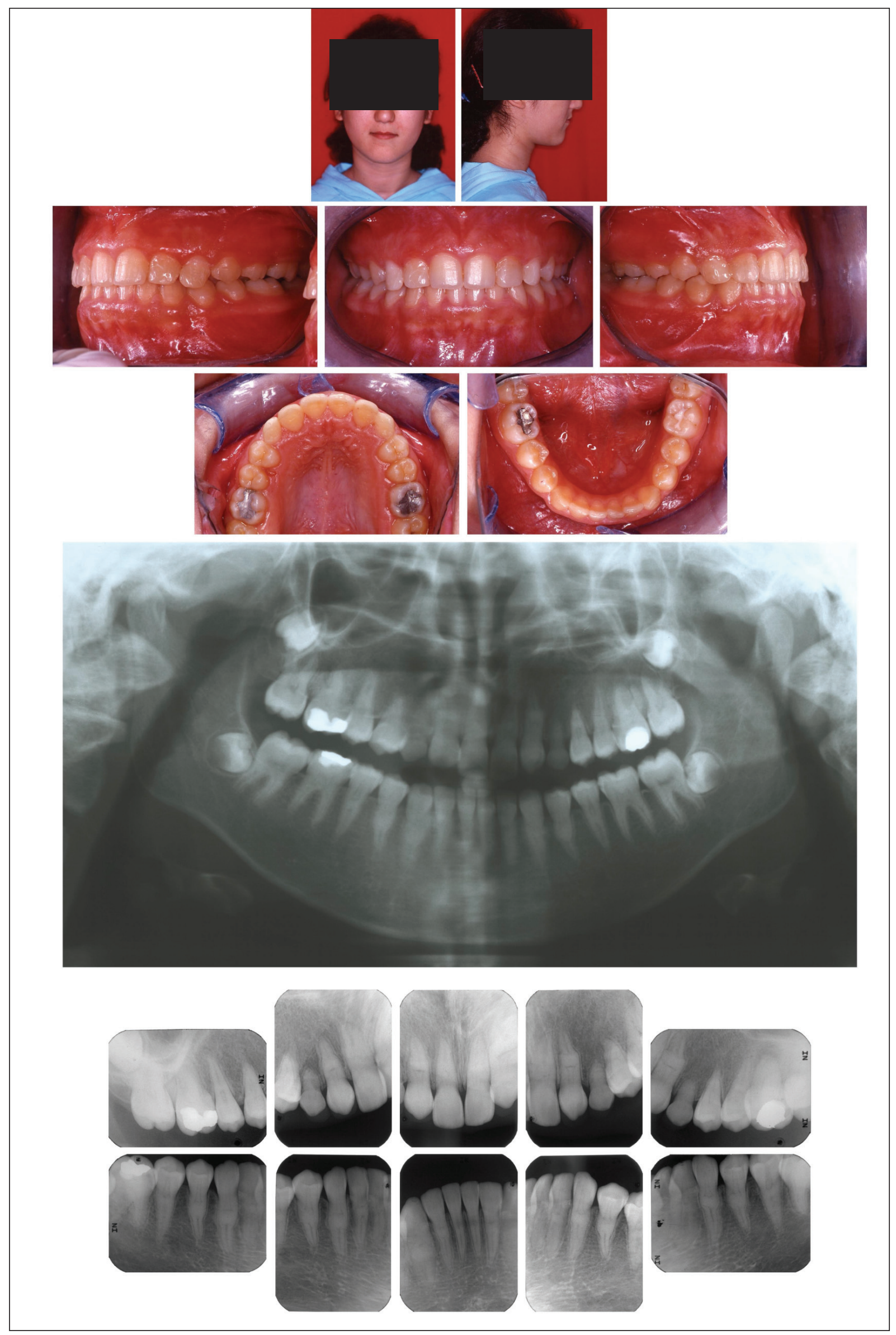

Figure 2. Posttreatment photographs and panoramic and periapical radiographs. 
agnosis based solely on traditional methods, ${ }^{2}$ the most likely diagnosis in the present case appears to be DD1d.

In the present case, we chose to treat the patient with fixed orthodontic appliances and subsequent composite restorations of the permanent and deciduous canines. The alternatives, extraction of the deciduous canines with mesialization of the posterior teeth, or the distalization of the permanent canines for lateral incisor implantsite development, were not considered feasible in this patient. According to Haselden et al, ${ }^{9}$ persisting primary canines are the most likely to show little or no resorption, and they give many years of service. These teeth can preserve dental arch integrity, providing alveolar bone for later implant therapy. Therefore, when planning treatment, the value of retaining the primary canines must be considered. ${ }^{9,10}$ Additionally, treating only the maxillary arch, with minor tooth movement, was thought to be advantageous in this case, due to the presence of pulp stones and atypical root shapes. It is well known that teeth with atypical root morphology are prone to root resorption. ${ }^{11}$ In addition, teeth with total pulp obliteration have a higher susceptibility to pulpal complications during orthodontic treatment. ${ }^{12,13}$

\section{CONCLUSIONS}

Here, we have reported the case of a patient with multiple pulp stones who was treated through a multi-disciplinary approach. We were able to establish a functionally and esthetically sound dentition via this approach.

\section{REFERENCES}

1. White SC, Pharoah MJ. Oral Radiology Principles and Interpretation. $4^{\text {th }}$ ed. St. Louis, Mosby, 2000.

2. Parekh S, Kyriazidou A, Bloch-Zupan A, Roberts G. Multiple pulp stones and shortened roots of unknown etiology. Oral Surg Oral Med Oral Pathol Oral Radiol Endod 2006;101:139142.

3. Witkop CJ Jr. Hereditary defects of dentin. Dent Clin North Am 1975;19:25-45.

4. Shields ED, Bixler D, El-Kafrawy AM. A proposed classification for heritable human dentine defects with a description of a new entity. Arch Oral Biol 1973;18:543-553.
5. O Carroll MK, Duncan WK, Perkins TM. Dentin dysplasia: Review of the literature and a proposed subclassification based on radiographic findings. Oral Surg Oral Med Oral Pathol 1991;72:119-125.

6. Tamse A, Kaffe I, Littner MM, Shani R. Statistical evaluation of radiologic survey of pulp stones. J Endod 1982;8:455-458.

7. Ranjitkar S, Taylor JA, Townsend GC. A radiographic assessment of the prevalence of pulp stones in Australians. Aust Dent J 2002;47:36-40.

8. Gulsahi A, Cebeci Al, Ozden S. A radiographic assessment of the prevalence of pulp stones in a group of Turkish dental patient. Int Endod J 2009;42:735-739.

9. Haselden K, Hobkırk JA, Goodman JR, Jones SP, Hemmings KW. Root resorption in retained deciduos canine and molar teeth without permanent successors in patients with severe hypodontia. Int J Paediatr Dent 2001;11:171-178.

10. Rozsa N, Nagy K, Vajo Z, Gabris K, Soos A, Alberth M, Tarjan I. Prevalence and distribution of permanent canine agenesis in dental paediatric and orthodontic patients in Hungary. Eur J Orthod 2009;31:374-379.

11. Malmgren O, Levander E. Minimizing orthodontically induced root resorption. In: Graber TM, Eliades T, Athanasiou AE (eds). Risk management in orthodontics: experts' guide to malpractice. Quintessence Publishing Co., Inc., Chicago; 2004: pp.61-73.

12. Bauss O, Röhling J, Meyer K, Kiliaridis S. Pulp vitality in teeth suffering trauma during orthodontic therapy. Angle Orthod 2009;79:166-171.

13. Bauss 0, Röhling J, Rahman A, Kiliaridis S. The effect of pulp obliteration on pulpal vitality of orthodontically intruded traumatized teeth. J Endod 2008;34:417-420. 